DOCTRINA

\title{
Análisis de la Ley 20.730: Sus características y desafíos
}

Analysis of Law 20.730: Its main characteristics and challenges

\section{María José Jordán Palet}

Pontificia Universidad Católica de Valparaíso, Chile

\begin{abstract}
RESUMEN En los Estados democráticos modernos la regulación del lobby ha sido un tema cada vez más importante. En este sentido, Chile se adscribió a dicha preocupación y tras una larga tramitación legislativa, aprobó la ley del lobby, Ley 20.730. El objetivo de este trabajo de investigación es analizar de forma generalizada los aspectos más relevantes de la referida ley y ciertos desafíos que ésta plantea a futuro.
\end{abstract}

PALABRAS CLAVE Lobby, Ley 20.730, registro de lobbistas.

\begin{abstract}
In modern democratic States, the regulation of lobbying activities has been an issue increasingly more important. In this sense, Chile has regulated this preoccupation and after an extensive legislative discussion, approved a law that regulates lobbying activities, which is Law 20.730. The purpose of this paper is to analyze in general the most important aspects of this piece of legislation and certain challenges it presents.
\end{abstract}

KEYWORDS Lobby, Law 20,730, lobbyist register.

\section{Antecedentes y argumentos que justifican la regulación del lobby en Chile}

\section{Los grupos de presión y su influencia en los sistemas democráticos}

Respondiendo a la pregunta sobre cómo se adoptan las decisiones dentro del proceso político, encontramos que los grupos de presión, para lograr su cometido, tienen como objetivo principal el de influenciar en la autoridad responsable de la decisión u abstención que ellos procuran obtener.

Una influencia exitosa de un grupo de presión dependerá en gran parte de si se escogió correctamente al destinatario objeto de su pretensión. Es así como los 
grupos de presión suelen dirigirse hacia donde ven más concentrado el poder y en manos de quienes está la facultad decisional en una sociedad democrática. De este modo, «el grado de influencia de estos grupos de presión, según algunos autores, tiene que ver con dos aspectos fundamentales: los sistemas políticos existentes en cada Estado, y la base democrática de los mismos» (Biblioteca del Congreso Nacional de Chile, 2002: 4).

Respecto de los sistemas políticos que inciden en la influencia del grupo de presión, existe una diferencia según si se trata de un país de sistema parlamentario o presidencialista. En el caso de un país de régimen de gobierno parlamentarista con férrea disciplina de partido, como por ejemplo en Inglaterra o España, los grupos de presión tenderán a centrar sus esfuerzos mayoritariamente en el Gobierno más que en el Parlamento. Lo anterior debido a que los parlamentarios estarán generalmente alineados según las directrices del partido y darán poca cabida a intereses diversos de aquéllos. En el caso de un régimen presidencial, como el de Estados Unidos, el mayor interés estará en influir sobre el Congreso más que el presidente, ya que es este órgano donde se concentra el mayor poder decisorio en dicho país (Von Beyme, 1980: 187) y además poseen sus parlamentarios un mayor grado de libertad al momento de decidir.

En Chile existe un régimen presidencialista en el que el presidente chileno tiene mayores poderes constitucionales, con lo que actúa muchas veces como un verdadero colegislador con el Congreso Nacional. Lo anterior debido a que el presidente puede controlar la agenda legislativa del Congreso mediante las urgencias, la iniciativa exclusiva de ciertos proyectos de ley, entre otros. No obstante, debido a los altos quórums exigidos por la Constitución Política de la República para aprobar ciertas leyes es que, si el presidente no cuenta con una mayoría parlamentaria que lo apoye, se tornará más difícil la posibilidad de aprobar su agenda política. De este modo, el interés de influir de un grupo de presión recaerá preponderantemente, a nuestro parecer, tanto en el órgano Ejecutivo como en el Legislativo.

Por otro lado, según la base democrática histórica y cultural de los sistemas políticos, se ha afirmado que en aquellos países donde se considera el interés general como supremo y absoluto, esto dificultaría en parte el éxito de las técnicas de influencia de los grupos de presión por ir en contra de este interés general. En cambio, en lugares donde la democracia es entendida como una vía para la búsqueda de la felicidad individual (por ejemplo, en Estados Unidos), aquí los diversos intereses particulares tienen mayor aceptación y cabida en su influencia al sistema político (Biblioteca del Congreso Nacional de Chile, 2002: 4).

Los alcances de esta influencia son diversos. En el mejor de los casos, si un grupo de presión llega a ser eficaz en la influencia que ejerce sobre la autoridad, se llega a conformar lo que se llama la tesis del gobierno invisible. Según esta tesis, el poder político estatal no es ejercido por los titulares que lo detentan, sino que por otros que están al margen de las instituciones políticas y que se caracterizan por su constante 
influencia en quienes son titulares del poder (Urzúa Valenzuela, 1986: 247). En otros casos, la influencia será menor o incluso nula. Esto dependerá del tipo de recursos al que pueda acceder el grupo de presión para influenciar, si escogieron adecuadamente el destinatario de su influencia o no, y los medios utilizados para aquéllo. Finalmente, es importante en este tema considerar que lo central a analizar no es si hay o no influencia de parte de los grupos de presión en la autoridad: la discusión debe girar en torno a si es legítima la forma en que esta es ejercida, y si acaso todos los ciudadanos tienen igual acceso a la autoridad para influir en ellas en igualdad de condiciones y no solamente determinados grupos privilegiados dentro de una sociedad (García, 2008: 109). Esta segunda hipótesis podría conllevar ciertos efectos negativos para la democracia, tales como la captura de la autoridad pública por algunos grupos económicos más influyentes, y el desmedro de la igualdad ante la ley y el derecho de peticionar a la autoridad que tienen todos los ciudadanos.

\section{Argumentos derivados de la ciencia política que justifican la regulación del lobby}

Se ha entendido lobbying como la «forma de influencia sistemática y permanente de grupos de interés económicos, sociales o también culturales en el proceso político de toma de decisiones» (Von Alemann y Eckert, 2012: 23).

Ahora bien, respecto de la interrogante de si el lobbying constituye una actividad legítima que debe ser regulada, es posible identificar tres respuestas generales. La primera de ellas considera el lobby como una actividad ilegítima (Lachmann, 2012: 5). Esto debido a que la autoridad o funcionario público debe velar siempre por el interés general de toda la sociedad y no restringirse a actuar sobre la base de ciertos intereses particulares que, incluso muchas veces, pueden contraponerse al interés de todos los ciudadanos. Además, en caso de considerarse legítimo el lobby y de estimarse necesaria su regulación, aquello acrecentaría aún más la desigualdad entre los ciudadanos, ya que no todos tienen en la práctica un acceso real a la autoridad. Una postura contraria a la anterior es que se acepta el lobby como legítimo y como necesario para el proceso democrático en la formulación de voluntad (Von Alemann y Eckert, 2012: 22), afirmando que sería una forma de concretar el derecho de petición ante la autoridad y el derecho de opinión que tienen las personas. También se esgrime como argumento de esta postura el hecho de que los lobbistas muchas veces aportan información valiosa a la autoridad sobre determinados temas al momento de adoptar una decisión.

Finalmente, una posición intermedia acepta que el lobby se pueda realizar dentro de la sociedad, pero que para evitar la corrupción y otros efectos negativos que esta actividad conlleva, debe transparentarse. De este mismo modo, en Chile, y en respaldo de la última postura, el Instituto Nacional de Derechos Humanos ha afirmado que: 
La regulación en este campo (del lobby o gestión de intereses) es necesaria para transparentar las relaciones entre autoridades públicas y grupos organizados de la sociedad, con el objeto de garantizar el derecho de toda persona a participar en igualdad de condiciones en el debate público, y observar que las decisiones de las autoridades se adopten en pos del bien común y no de intereses particulares (INDH, 2012: 115).

Nuestro país no ha estado ajeno a esta discusión. En los últimos años ha habido diversos escándalos públicos que involucran conductas poco transparentes, y que, en gran parte, se relacionan con el lobby ejercido ante autoridades y funcionarios públicos. ${ }^{1}$ Es así cómo

la idea entre dinero y la política y su necesidad de regulación ha pasado a ser un lugar común en la discusión pública, del mismo modo que el término «captura»o "captura regulatoria $»^{2}$ ha pasado a ser parte del vocabulario obligado de los interesados en temas de políticas públicas. Subyacente a este tipo de temas se encuentra, en último término, la idea de preeminencia del interés privado por sobre el público (Guzmán Romero, 2008: 10).

De este modo, la percepción ciudadana del lobby ha sido identificada en Chile como algo negativo y perjudicial para el bien común. Una encuesta realizada por el Barómetro de Corrupción Global el año 2013 estableció que el «68\% de los encuestados cree que existe corrupción en el Parlamento». ${ }^{3}$ Por otro lado, la percepción de políticos y autoridades pareciera ir en la misma línea de la ciudadanía: es necesario regular del lobby para hacer más transparente el proceso de toma de decisiones. ${ }^{4}$

1. Casos como aquello ha sido el de la diputada Marta Isasi, que recibió 25 millones de pesos por el grupo Angelini en la tramitación de la Ley de Pesca; las declaraciones del exministro Jaime Mañalich respecto del lobby farmaceútico; el caso de Soquimich, respecto de los correos electrónicos enviados al senador de la época Pablo Longueira discutiendo el proyecto de Royalty Minero, entre otros. En relación con quiénes son estos actores de lobby en Chile, un estudio realizado por la Universidad Diego Portales concluyó que «los más mencionados son los «dirigentes gremiales y empresariales» $(74 \%)$ y los» ex funcionarios de gobierno y exparlamentarios» $(68 \%)$. Una cantidad intermedia de menciones reciben las «empresas de lobby reconocidas como tales» (50\%), los estudios de abogados (41\%) y «las empresas de comunicación estratégica e imagen» (38\%)» (Instituto de Ciencias Sociales de la Universidad Diego Portales, 2005: 7).

2. La captura regulatoria se puede entender como el «predominio del interés privado por sobre el público en el devenir de la actividad política y pública» (Guzmán Romero, 2008: 11).

3. «Chile», Transparency International, Global Corruption Barometer, 2013, disponible en http://bit. ly/2Bgus 4 B.

4. Una encuesta realizada a representantes políticos por el Instituto de Ciencias Sociales de la Universidad Diego Portales el año 2005, concluyó que «existe bastante acuerdo entre los políticos entrevistados de que el lobby «es una actividad que debería ser legalizada para hacerla más transparente» (86\%). Por su parte, sólo el $7 \%$ considera que «es una actividad ilegítima que debería ser prohibida y penalizada», mientras que el 6\% cree que «es una actividad legítima que no requiere regulación»» (Instituto de Ciencias Sociales de la Universidad Diego Portales, 2005: 2). 
Es así como los ciudadanos suelen identificar el lobby con una actividad:

poco transparente, asumida como tal. Porque se la identifica con la pugna por ventajas inapropiadas o ilegitimas; con acciones que, en la oscuridad del contacto privado, se acerca a la frontera del tráfico de influencias, entendido como pactos de ventajas mutuas - presentes o futuras - entre la empresa y el regulador o decisor público (Correa Ríos, 2010: 103).

Reafirmando esta situación, una auditoría del Programa de las Naciones Unidas para el Desarrollo (PNUD) destacó el contexto en el cual se desenvuelve realmente la democracia chilena. Ese estudio concluyó que

«existen déficits en la calidad y mecanismos de representación política que favorecen a unos y perjudican a otros, excluyendo a sectores de los espacios de poder y restando capacidad de incidir en las decisiones que se toman para el colectivo. [...] Existen problemas aún persistentes de tráfico de influencias, conflictos de intereses y lobby por sectores con mayores recursos materiales y simbólicos que permiten que éstos predominen en la deliberación política». Por lo mismo, esto conlleva a que «la política y los asuntos públicos le son ajenos, distantes y poco transparentes a parte importante de la población, apartándolos de espacios de decisión y deliberación limitando la posibilidad de ciertos grupos de apropiarse de los derechos que la democracia ofrece» (PNUD, 2014: 38).

En apoyo de esta visión es que se ha planteado que «las prácticas corruptas, por lo general, traen como consecuencia la desigualdad y la discriminación en el disfrute de los derechos humanos» (INDH, 2012: 115). A raíz de esto es que las políticas públicas han avanzado gradualmente en combatir la corrupción y la desconfianza ciudadana en las instituciones. De este modo, «el Estado de Chile comenzó una serie de modificaciones legales tendientes a transparentar el quehacer público - carrera funcionaria, gasto electoral, declaración jurada patrimonial y de intereses, entre otros aspectos- y fomentar el control social» (INDH, 2012: 115).

Dentro de las medidas legislativas que el Estado de Chile se ha preocupado en adoptar ha sido la regulación de la actividad del lobby. De esta forma,

el Gobierno de Chile, en enero del año 2003, luego de que la opinión pública conociera diferentes casos de corrupción —-donde estaban involucradas altas autoridades públicas- pactó con los partidos políticos de oposición el denominado «Acuerdo Político-Legislativo sobre Modernización del Estado, Transparencia y Promoción del Crecimiento», dentro del cual se incluyó la aprobación de una ley de regulación de la gestión de intereses o lobby (Castro Pedrero, 2004: 13).

Ahora bien, en relación con los argumentos de por qué debe legislarse respecto del lobby, la ciencia política ha planteado que las democracias contemporáneas están 
inmersas en mejorar lo que se denomina la «buena gobernanza». Este concepto tiene cuatro aspectos a considerar: la transparencia de las actuaciones de los funcionarios públicos y el Poder Legislativo y Judicial, ${ }^{5}$ la rendición de cuentas o accountability, la participación ciudadana y la probidad en la gestión pública. En relación con este último aspecto, debe recalcarse que el principio de probidad fue incorporado tras las reformas del año 2005 con la Ley 20.050, al artículo 8 de la Constitución Política de la República. El principio de probidad puede entenderse como el deber que toda autoridad tiene de actuar de forma que otorgue preeminencia a los intereses generales por sobre los particulares al momento de tomar decisiones. ${ }^{6}$ Dicho principio está directamente relacionado con el lobby, por cuanto se ha entendido que,

La probidad no puede ser considerada como tal si no se le asocia a la transparencia, es decir, a la voluntad permanente de decidir sobre la cosa pública abiertamente, permitiendo que los ciudadanos conozcan los fundamentos y razones de la decisión, además de cómo ésta se ejecuta (Vivanco Martínez, 2008: 385).

Es decir, quienes apoyan la necesidad de la regulación del lobby estiman que al ser ésta una actividad que se realiza durante el proceso de toma de decisiones, se torna sumamente importante transparentar aquello para saber qué intereses está resguardando la autoridad al momento de actuar en ejercicio de sus funciones: si acaso vela por un interés general o actúa en favor del interés de determinado lobbista.

En este sentido, una adecuada regulación de la actividad del lobby puede contribuir a «garantizar el derecho de toda persona a participar en igualdad de condiciones en el debate público y observar que las decisiones de las autoridades de adopten en pos del bien común y no de intereses particulares» (INDH, 2012: 115). En virtud de lo anterior es que se plantea la regulación del lobby como una posible solución y forma de evitar prácticas poco transparentes o poco corruptas, mediante una normativa que sea omnicomprensiva de las herramientas necesarias para evitar actividades ilícitas.

\section{Argumentos jurídicos para regular el lobby en Chile}

No obstante, la regulación de la actividad de lobby no es suficiente para combatir la corrupción y las actividades ilícitas. Junto con la regulación del lobby, es necesario contemplar otras normas para que dicha legislación sea realmente eficiente. En este

5. De este modo, García García y Soto Velasco plantean que, a raíz del bicameralismo existente en Chile, «nuestra institucionalidad ha respondido desde los inicios de su vida independiente a un modelo que dificulta la captura de los grupos de interés y aumenta el consenso necesario para aprobar las leyes» (García García y Soto Velasco, 2015: 358).

6. El principio de probidad administrativa según el artículo 52 de la Ley 18.575 consiste en «observar una conducta funcionaria intachable y un desempeño honesto y leal de la función o cargo, con preeminencia del interés general sobre el particular». 
sentido se plantea el establecimiento de Códigos de Conducta para los funcionarios públicos, la penalización de influencias indebidas en el proceso de toma de decisiones (como los delitos de cohecho, malversación, tráfico de influencias, etcétera); la consagración del derecho de petición de toda persona y de libertad de expresión, políticas que fomenten la participación ciudadana, estándares y procedimiento de acceso a la información y reglas sobre los partidos políticos y el financiamiento de campañas políticas (OCDE, 2009: 23).

Dentro de los argumentos normativos, encontramos que, a nivel internacional, debe considerarse que la regulación del lobby por el Estado de Chile constituía una obligación internacional que se demoró varios años en cumplirse. Es así como el artículo 5 números 2 y 3 de la Convención de Naciones Unidas Contra la Corrupción establece que «cada Estado parte procurará establecer y fomentar prácticas eficaces encaminadas a prevenir la corrupción» y, por lo mismo, "procurará evaluar periódicamente los instrumentos jurídicos y las medidas administrativas pertinentes a fin de determinar si son adecuados para combatir la corrupción». ${ }^{7}$

En las bases de la institucionalidad, el inciso final del artículo 1 de la CPR establece el deber del Estado de «asegurar el derecho de las personas a participar con igualdad de oportunidades en la vida nacional». Por otro lado, en el capítulo 3 referido a los «derechos y deberes constitucionales», en el artículo 19 número 2 se establece el principio de «la igualdad ante la ley. En Chile no hay persona ni grupo privilegiados».

Estos dos principios están íntimamente relacionados con la actividad del lobby, ya que la ausencia de su regulación dificulta la concreción de la igualdad ante la ley y la igualdad de oportunidades en la participación en asuntos públicos, puesto que determinados grupos con acceso a información privilegiada, con mayor influencia por su posición económica o por ser sectores más representativos de la sociedad, pueden tener el monopolio en el acceso a las autoridades y funcionarios públicos. ${ }^{8}$

Este argumento es, a su vez, concordante la postura de García, quien señala que:

pareciera obvio que el tema en discusión no es la influencia per se, sino su legitimidad, esto es, la forma en que ésta es ejercida y las oportunidades que todos tienen para sacar ventajas de aquéllas, en otras palabras, lo que debe ser preservado es la competencia entre los participantes de la carrera de la influencia (García, 2008: 110).

7. Otros artículos relevantes son el artículo 10 y también el artículo 13 número 1 letra a de la citada Convención.

8. En este mismo sentido se pronunció la entonces diputada Carolina Tohá entonces al señalar durante la discusión general del Boletín 3.407-07 del año 2003: «El lobby es una actividad delicada, porque consiste en tratar de obtener de la autoridad atención preferente por determinados intereses, determinados incluso por intereses propios. Por eso, si el lobby no está regulado y previstas todas las posibles situaciones, puede transformarse, con mucha facilidad, no sólo en un factor de distorsión de la democracia, sino de acentuación de las inequidades sociales». 
Además, es menester señalar el artículo 19 número 14 de la CPR que consagra la posibilidad de "presentar peticiones a la autoridad, sobre cualquier asunto de interés público o privado, sin otra limitación que la de proceder en términos respetuosos y convenientes». Se ha considerado que el lobby es una concreción fáctica del derecho de peticionar de toda persona (OCDE, 2009: 44) debido a que dentro del contenido material de este derecho, incluye la solicitud en asuntos de interés particular o general por parte de un ciudadano a la autoridad.

De esta forma se torna necesaria la regulación de la actividad de lobby no sólo para transparentar dichas acciones, sino que para resguardar el principio de probidad y darle un cumplimiento más estricto.

El presente artículo, en primer lugar, describirá someramente cómo fue la discusión parlamentaria sobre la regulación del lobby, abordando los dos proyectos de ley en la materia y la indicación sustitutiva del Ejecutivo. En segundo lugar, se expondrán las principales características de la Ley 20.730 y sus vacíos legislativos. Finalmente, se efectuará una comparación entre la herramienta regulatoria por la cual optó la legislación chilena, esto es, el Registro de Agenda Pública con el Registro de Lobbistas.

\section{Discusión parlamentaria sobre regulación del lobby: Dificultades legislativas en su aprobación}

\section{Proyectos de ley más relevantes sobre la regulación del lobby}

Es sabido que cualquier regulación del lobby debe tener por objeto transparentar el proceso de toma de decisiones y contener herramientas que hagan posible la igualdad de acceso de los ciudadanos a la autoridad estatal.

Pese a la evidente obligación internacional y las normas constitucionales relacionadas en este aspecto, en Chile pasaron más de diez años de intentos legislativos para regular el lobby hasta que se aprobara en definitiva la Ley 20.730, que «regula el lobby y las gestiones que representen intereses particulares ante las autoridades y funcionarios». En este sentido, los proyectos más relevantes fueron el Boletín 3.407-07 del año 2003 y el Boletín 6.189-06 del año 2008.

Es importante destacar que el proyecto que derivó en la Ley 20.730 corresponde a la iniciativa que data del año 2008, ya que la tramitación del proyecto del año 2003 se detuvo ese mismo año, comprometiéndose el Ejecutivo a enviar al Congreso un nuevo proyecto que incorporase las observaciones que tanto los parlamentarios como especialistas habían hecho presentes durante la tramitación legislativa. ${ }^{9}$

Pese a ello, la idea de ambas iniciativas era lograr que los funcionarios públicos y los parlamentarios actuaran de manera proba y transparente, representando los inte-

9. Este proyecto constaba de 24 disposiciones y dos artículos transitorios. 
reses públicos sin dejarse llevar por medios de influencia ilícitos de grupos de presión al momento de adoptar sus decisiones.

El objeto central de la discusión de estos proyectos fue determinar de qué forma se permitiría que se realice dicha actividad; quiénes serían considerados lobbistas; cuáles serían los estándares de conducta que deberían tener quienes deseen realizar esa actividad; y cómo proveer de una buena regulación para no generar desigualdades en el acceso a la autoridad al momento de plantear sus posiciones e intereses respecto de un tema determinado.

\section{Contenidos de los mencionados proyectos de ley}

Ambos proyectos tuvieron una base común: el modelo estadounidense de regulación de lobby de conformidad con lo establecido en la Lobbying Disclosure Act (1995).

Lo anterior se ve plasmado en el mensaje presidencial del proyecto del año 2008. Del mismo modo, las características principales de ambos proyectos son concordantes con el modelo estadounidense, puesto que: a) regulaban el lobby ejercido de forma profesional, ${ }^{10}$ b) creaban una serie de registros de lobbistas, ${ }^{11}$ c) establecían prohibiciones y obligaciones para los lobbistas profesionales ${ }^{12} \mathrm{y}$, como consecuencia de lo anterior, d) el foco principal de la legislación era el lobbista o sujeto activo.

Ambos proyectos, en su formulación original, contemplaban la creación de un Registro de Lobbistas.

En ambos proyectos legislativos se estableció como requisito que quienes desearen ejercer lobby profesionalmente debían inscribirse previamente en un Registro de Lobbistas. A su vez, se instituía que las autoridades y parlamentarios que fuesen sujetos pasivos de esta actividad tenían la obligación de informar sobre las reuniones sostenidas con los lobbistas, así como la materia tratada durante ellas.

En cuanto a la eficacia de esta propuesta, era criticable por el hecho de que hubiese existido una pluralidad de registros de lobbistas según ambos proyectos, ${ }^{13}$ lo que

10. Se define en esta legislación a los lobbistas como: «The term «lobbyist» means any individual who is employed or retained by a client for financial or other compensation for services that include more than one lobbying contact, other than an individual whose lobbying activities constitute less than twenty percent of the time engaged in the services provided by such individual to that client over a six month period». Traducido, se entendería como «El término «lobbista» [también conocido en español como "cabildero»] hace referencia a cualquier individuo que es empleado o retenido por un cliente para efectos de obtener una compensación financiera o de otro tipo, por servicios que incluyen más de un contacto de lobby, y que a su vez no sea un sujeto cuyas actividades de lobby constituyan menos del veinte\% del tiempo dedicado al servicio proporcionado por éste a ese cliente durante un período de seis meses».

11. Sección 4 de la LDA, relativa a los «registros de lobbistas».

12. Sección 7 de la LDA, relativa a las "penalidades».

13. A modo de ejemplo, en el proyecto del 2003 se contemplaban 3 registros de lobbistas y en el artículo 11 del proyecto 2008 se contemplaban 5 registros distintos y a cargo de distintos órganos. 
burocratizaba la obligación de inscripción del lobbista, al tener que inscribirse en el registro correspondiente para poder realizar lobby ante determinado órgano o institución. De haberse aprobado de esta forma la iniciativa legislativa, aquello probablemente hubiese conllevado a que en la práctica no se cumpliese con aquel imperativo. Y, por otro lado, quizás un número muy reducido de personas que se reconocen como lobbistas profesionales se hubiesen inscrito, ya que muy pocas personas querrían ser identificados como tal por el resto de la sociedad.

\section{Indicación sustitutiva del Ejecutivo ${ }^{14}$}

La discusión del proyecto del año 2008 se paralizó en julio de 2009, en su segundo trámite constitucional. No fue hasta casi tres años después que se reanudó la discusión tras la indicación sustitutiva presentada por el entonces presidente Sebastián Piñera. Esta indicación sustitutiva fue formulada en el año 2012, y contenía una serie de nuevas propuestas: a) se establece como objeto de la regulación el fortalecimiento de la transparencia de las relaciones con el Estado y sus organismos; b) se restringen las excepciones al concepto de lobby; c) también se regula de forma más detallada que en el proyecto original lo relativo a la publicidad de las audiencias, disponiendo que los datos de éstas deben publicarse en el sitio web del sujeto pasivo y de manera actualizada, al menos una vez al mes - en el proyecto original, la determinación del plazo de publicación estaba entregada al reglamento-, y finalmente, d) se tipifican y detallan más las sanciones y el procedimiento para determinar la infracción y sanción correspondiente (Biblioteca del Congreso Nacional de Chile, 2012: 5-6).

Los propósitos de esta nueva indicación se fundaban en la pérdida de confianza de los ciudadanos en las instituciones públicas y su funcionamiento. Se buscó revertir dicha situación a través de tres principios: el primero de ellos era la igualdad de acceso a la autoridad, el segundo se traducía en la imparcialidad de la autoridad y el tercero en la transparencia de las actividades públicas. ${ }^{15}$

De este modo, y con esta indicación sustitutiva por parte del Ejecutivo, es posible afirmar que en la tramitación de la ley del lobby en Chile existieron dos modelos posibles en discusión por parte de los parlamentarios. El primero de ellos, y que se identifica con los proyectos del año 2003 y 2008, sería el modelo más bien de carácter «estatutario», que consagraba la existencia de Registros de Lobbistas obligatorios, además de prohibiciones y restricciones a quiénes ejercerían lobby. El segundo modelo planteado, y que se identifica con la indicación sustitutiva del Ejecutivo, fue el modelo de transparencia de la función pública. Conforme se expondrá en este acápite

14. Se utilizó también para esta sección la información disponible en Biblioteca del Congreso Nacional de Chile (2012b: 4-6).

15. Historia Fidedigna de la Ley 20.730, folio 259. 
y en el siguiente, este es el modelo por el que finalmente se optó por el Legislador chileno.

Esta indicación sustitutiva constituyó un cambio de paradigma de las discusiones anteriores, pues amplió el ámbito de aplicación de la ley en tres aspectos: i) eliminó la lista de entidades cuyas actividades no serían consideradas como lobby, ii) modificó el objeto de la ley al regular no sólo el ejercicio del lobby profesional, sino también la representación de cualquier interés particular ante la autoridad y, finalmente, iii) agregó como conducta de lobby aquélla que persigue que la autoridad se abstenga de tomar una decisión. ${ }^{16}$ Del mismo modo, en relación con los sujetos pasivos del lobby, se aumentó el espectro de autoridades que podía ser objeto de lobby. ${ }^{17}$

Finalmente, lo más novedoso de esta indicación fue que se cambió su foco de regulación. El foco regulatorio en el proyecto legislativo de los años 2003 y 2008 eran los lobbistas o sujetos activos de lobby, y con esta indicación sustitutiva la ley se centró en los sujetos pasivos de dicha actividad, esto es, las autoridades o funcionarios públicos. Este cambio se enmarca en la lógica de que los funcionarios públicos o autoridades son los guardianes del interés general de la comunidad y la responsabilidad última recae en ellos, ya que son éstos quienes deben evitar que el interés general de la comunidad quede en desmedro por la preeminencia de intereses particulares en las decisiones adoptadas.

Como consecuencia de dicho cambio, se propuso eliminar el Registro de Lobbistas y sustituirlo por un Registro de Agenda Pública. Este registro debía ser publicado en un sitio web visible, a cargo del Ministerio de Secretaría General de la Presidencia. En él, la autoridad o parlamentario publicaría información relativa a la reunión sostenida con cualquier persona que solicite una audiencia, y los viajes realizados en el ejercicio de sus funciones, indicando siempre el origen de los fondos. Finalmente, con esta indicación, se eliminaban las obligaciones y prohibiciones de los lobbistas.

\section{Ley 20.730: Contenido y principales características}

\section{Características de la Ley 20.730}

La Ley 20.730 fue publicada el 8 de marzo de 2014 en el Diario Oficial. Consta de veinticinco artículos y dos disposiciones transitorias. En relación con su ámbito de aplicación, el artículo 1 de esta normativa establece que «regula la publicidad en la actividad de lobby y demás gestiones que representen intereses particulares, con el

16. Historia Fidedigna de la Ley 20.730, folio 261.

17. Se incorporan nuevas autoridades, tales como los directores regionales de los servicios, los encargados de las adquisiciones de las Fuerzas Armadas y de Orden y Seguridad Pública y jefe y subjefe del Estado Mayor Conjunto, el fiscal nacional y fiscales regionales, entre otros. 
objeto de fortalecer la transparencia y probidad en las relaciones con los órganos del Estado». ${ }^{18}$

A continuación, analizaremos ciertos aspectos fundamentales de la ley de lobby recientemente aprobada, tales como: i) el concepto de lobby, ii) los sujetos regulados, iii) el Registro de Agenda Pública, y iv) las obligaciones impuestas por la ley.

\section{Concepto de lobby según la Ley 20.730}

Esta norma define el lobby en su artículo 2 número 1) como:

Aquella gestión o actividad remunerada, ejercida por personas naturales o jurídicas, chilenas o extranjeras, que tiene por objeto promover, defender o representar cualquier interés particular, para influir en las decisiones que, en el ejercicio de sus funciones, deban adoptar los sujetos pasivos que se indican en los artículos 3 y 4.

Lo anterior incluye los esfuerzos específicos para influir en el proceso de toma de decisiones públicas y cambios en las políticas, planes o programas, en discusión o en desarrollo, o sobre cualquier medida implementada o materia que deba ser resuelta por el funcionario, la autoridad o el organismo público correspondiente, o bien para evitar tales decisiones, cambios y medidas.

En relación con lo que se entiende por «interés particular» dentro del concepto de lobby, la ley lo define en su artículo 2 número 4 como «cualquier propósito o beneficio, sean o no de carácter económico, de una persona natural o jurídica, chilena o extranjera, o de una asociación o entidad determinada». En este sentido, en la discusión legislativa en torno a este artículo, los representantes del Ejecutivo destacaron que

el concepto, dada su amplitud, incluiría al Banco Estado o a una universidad pública que podrían realizar una gestión de interés particular en pos de un beneficio susceptible de solicitar a una autoridad. Sostuvieron que esta amplitud era uno de los puntos altos de esta iniciativa, toda vez que no se distinguía si se trataba de una empresa pública o privada la que realizaba lobby o era o no lobbista, sino que lo que importaba era que tal gestión quedara plasmada en el registro de audiencias. ${ }^{19}$

En síntesis, lo que se buscó con este concepto de lobby era que cualquier reunión sostenida fuera registrada, independiente si el interés detrás gestionado era particular o no.

18. En este mismo sentido, la Contraloría General de la República ha reconocido: «En tal sentido, es pertinente destacar que acorde a lo estatuido en el artículo 1 de la citada Ley 20.730, ésta apunta a hacer efectivos dos principios de gran relevancia en nuestro ordenamiento, como lo son los de transparencia y probidad, permitiendo a la ciudadanía y, por cierto, también a las asociaciones de funcionarios, conocer las actividades de lobby y de gestión de intereses particulares que desarrolle una persona natural o jurídica - incluida otra asociación - ante las autoridades y funcionarios respectivos, a fin de influir en las decisiones que estos deben adoptar en el desempeño de sus cargos» (Dictamen 11.897 de 2017).

19. Historia Fidedigna de la Ley 20.730, folio 322. 


\section{Sujetos regulados por la Ley 20.730}

En relación con los sujetos regulados por esta ley, existe por un lado el sujeto activo, quien ejerce el lobby sobre determinada persona, y, por otro lado, los sujetos pasivos, que son las autoridades y funcionarios públicos receptores del lobby. Respecto de este punto, en la sentencia del Tribunal Constitucional del 31 de enero de 2004, rol 2.619-14-CPT, que efectuó el control preventivo y obligatorio del proyecto de ley en cuestión, en el voto de los ministros Raúl Bertelsen, Iván Aróstica y María Luisa Brahm, se señaló:

5: [...] la determinación de quienes serán sujetos pasivos de lobby dentro de la Administración, que es lo que hace el artículo 3 del proyecto de ley en examen, es un asunto que incide en la organización básica de la Administración Pública y en la aplicación en un ámbito específico de principios propios de la ley orgánica constitucional como son los de probidad, transparencia y publicidad.

Respecto del sujeto activo de la Ley 20.730, estos pueden ser dos personas: un lobbista o gestor de intereses particulares. En este sentido, la diferencia entre uno y otro es que si no media una remuneración se denominará gestor de intereses. Esta última figura llama la atención enormemente, ya que se entiende bajo esta ley que quien realiza lobby es el lobbista, y el gestor de intereses particulares (pese a que la ley no lo diga), sería un ciudadano que estaría ejerciendo su derecho a peticionar ante cualquier autoridad. Por ende, la Ley 20.730 pareciera tener un ámbito de aplicación más amplia que solamente la regulación específica de lobby. De este modo, la Ley 20.730 pareciera tener por objeto la regulación de las reuniones que sostienen las autoridades o funcionarios públicos en general. ${ }^{20}$

Por otro lado, y en relación con los sujetos pasivos regidos por esta ley, encontramos que el artículo 3 y 4 enumera quiénes serán, pero no de forma taxativa, puesto que el artículo 4 incisos segundo y tercero establecen la posibilidad de que se incluyan nuevos sujetos pasivos mediante resoluciones o acuerdos en las instituciones u órganos correspondientes. ${ }^{21}$ Es curioso que la Ley 20.730 nada diga respecto del

20. La anterior afirmación es concordante con lo expresado por el ministro de aquella época, Cristián Larroulet, quien afirmó en la discusión en sala del proyecto: «¿Qué hace la iniciativa? Fundamentalmente, regular el lobby, pero poniendo énfasis en un aspecto: la transparencia. Los países que han legislado sobre este asunto siguen distintos modelos. Nuestra proposición se centra en la transparencia. Ella es el mejor antídoto contra la corrupción; es el mejor mecanismo para darle legitimidad y confianza al rol de las instituciones públicas». Ver en este sentido la Historia Fidedigna de la Ley 20.730, folio 524.

21. Ahora bien, respecto de quiénes pueden ser entendidos como sujetos activos según la Ley 20.730, la Contraloría ha precisado respecto de las asociaciones de funcionarios de la administración que: «En consideración a lo anterior y a que de lo estatuido en el artículo 7 de la aludida Ley 19.296, se advierte que las asociaciones de funcionarios de la Administración tienen por finalidad promover el mejoramiento 
presidente de la República como sujeto pasivo del lobby, a pesar de que sí se incluye en la misma a los ministros y subsecretarios correspondientes. Si se sigue la lógica del listado de los sujetos pasivos de la Ley 20.730, muchas de las autoridades que son electas fueron incluidas como sujetos pasivos, por lo que no se evidencia la razón de excluir la agenda pública del presidente de la República. Ahora bien, y en relación con este punto, en la sentencia del Tribunal Constitucional, de 31 de enero de 2004, rol 2.619-14-CPT, que efectuó el control preventivo y obligatorio del proyecto de ley en cuestión, en el voto de los ministros Raúl Bertelsen, Iván Aróstica y María Luisa Brahm, se señaló que,

7: [...] la exclusión en el proyecto de ley de toda regulación de la actividad de lobby que pueda ejercerse sobre el presidente de la República, que es la más alta autoridad del Estado, con responsabilidades efectivas de gobierno y administración, [...] representa una omisión carente de justificación y de asidero en la Carta Fundamental, constitutiva de una omisión inconstitucional que no está, sin embargo, en manos del Tribunal Constitucional remediar, aunque sí le corresponda constatarla.

Una interesante situación se presenta en el inciso cuarto del artículo 4, que faculta a cualquier persona para solicitar por escrito la incorporación de un funcionario público como sujeto pasivo de la ley ante el jefe de servicio en que se desempeña. De esta forma, no se puede afirmar que la lista de sujetos pasivos de la Ley 20.730 sea taxativa, ya que esta regulación deja abierta la posibilidad de incluir nuevos funcionarios públicos o autoridades.

\section{Registros de Audiencia Pública²}

La ley crea un tipo de registro a cargo de diversos órganos del Estado llamado Registros de Audiencia Pública. Estarán a cargo de las instituciones al que pertenezca el sujeto pasivo (como, por ejemplo, las Fuerzas Armadas, Consejo de Defensa del Estado, la administración comunal y regional, etcétera). También habrá un registro a cargo de Contraloría General de la República; uno a cargo del Banco Central y dos registros a cargo del Congreso Nacional (Cámara de Diputados y el Senado), cada uno administrado por las Comisiones de Ética y Transparencia. Asimismo, se contempla un registro a cargo del Ministerio Público y uno a cargo de la Corporación Administrativa Judicial.

Estos registros deberán consignar los requerimientos del artículo 8 de la ley. Es-

económico y de las condiciones de vida y de trabajo de sus afiliados y, en general, defender o representar los intereses de ellos, los dictámenes 87.972, de 2015, y 18.251, de 2016, han precisado que tales agrupaciones pueden realizar actividades regidas por la Ley 20.730 y que, por lo tanto, en caso de desarrollarlas debe cumplirse con lo ordenado por dicha normativa». Dictamen 11.897 de 2017.

22. Para más información al respecto, véase Biblioteca del Congreso Nacional de Chile (2012a). 
tos requerimientos se pueden resumir en los siguientes: i) en estos registros deben constar las audiencias y reuniones sostenidas por la autoridad; ii) la autoridad debe consignar la organización o entidad con quien se sostuvo la audiencia o reunión, iii) a nombre de quién se gestionan los intereses, iv) los presentes en la reunión, v) si se recibe remuneración por las gestiones y vi) el lugar de la reunión, la fecha y la materia tratada. También deben constar los vii) viajes realizados por los sujetos pasivos en el ejercicio de sus funciones $y$, además, debe consignarse los donativos oficiales y protocolares. ${ }^{23}$

La información contenida en éstos deberá publicarse y actualizarse al menos una vez al mes y a su vez, el Consejo para la Transparencia hará trimestralmente una nómina sistematizada de las personas que sostengan reuniones con los sujetos pasivos.

En el inciso segundo del artículo 13 de la ley se establece que se podrá inscribir en los Registros automática o previamente a que se efectúen las reuniones.

Ahora bien, esta herramienta regulatoria será analizada en la sección final de este trabajo, ya que el Registro de Lobbistas fue un elemento central de la discusión, por lo que amerita un análisis mayor.

\section{Obligaciones establecidas en la ley}

Respecto a las obligaciones establecidas en la ley, debe resaltarse que se consagran obligaciones principalmente para la autoridad o funcionario público más que para el lobbista.

Ahora bien, dentro de las obligaciones del funcionario público, existe una norma que llama la atención, que es el artículo 11, que consagra el principio de «igualdad de trato» respecto de las «personas, organizaciones y entidades que soliciten audiencias sobre una misma materia». La finalidad perseguida con dicho principio es que ni la autoridad ni el funcionario público, al serles solicitado una audiencia por distintos sujetos pasivos, confirmen la audiencia para un tipo de grupo de personas y no para otras.

23. Respecto de qué audiencias deben o no consignarse en este Registro de Audiencia Pública, la Contraloría ha señalado lo siguiente en el Dictamen 13.392 de 2016: «Al respecto, corresponde puntualizar que en la medida que una persona se reúna con el sólo propósito de comunicar la existencia de un ilícito a la autoridad comunal, sin pretender influir en alguna decisión que ésta deba tomar en ejercicio de sus atribuciones, no se estará ante una situación que tenga que ser incluida en el mencionado registro de agenda pública, conforme a la preceptiva en análisis». Respecto de estos registros de donativos, la Contraloría ha señalado en el Dictamen 3.656 de 2016: «De la preceptiva antes reseñada, se colige que la prohibición de aceptar donativos está dirigida a los funcionarios de la Administración sin afectar la potestad de que gozan las instituciones públicas para recibir donaciones, ya que ambas normas tienen un ámbito de acción diferente y pueden coexistir sin afectar la finalidad de la otra, según lo señaló el Dictamen 30.441, de 2016, de este origen». 
En este sentido, el lobbista o gestor sólo tiene las obligaciones estipuladas en el artículo 12 de la Ley 20.730. Este artículo se puede resumir como una sola obligación: la de informar al sujeto activo ciertos datos. Esta obligación se descompone en cuatro aspectos: a) el primero es el de proporcionar información de forma oportuna y veraz a las sujetos pasivos tanto para solicitar audiencias o reuniones como para su publicación; b) el segundo se trata de informar al sujeto pasivo el nombre de las personas o entes representados en su caso; c) el tercer aspecto dice relación con informar si recibe una remuneración por las actividades realizadas o no, y d) en el caso de las personas jurídicas, dar la información que se les pida respecto de su estructura y conformación.

La ley contempla en el referido precepto que ante la omisión de esta obligación de proporcionar información o incluir información inexacta o falsa a sabiendas, se les impondrá a los lobbistas o gestores de intereses la multa del artículo 8, y esta fluctúa entre 10 y 50 UTM. Existe un vacío legal en esta materia, por cuanto ni en el artículo 8 ni en el referido artículo 12 contemplan un procedimiento de aplicación de multas ni quién sería la autoridad encargada de aquello.

\section{Reglamentos de la Ley 20.730}

La Ley 20.730 disponía en su artículo segundo transitorio un período de vacancia legal hasta la publicación de ciertos reglamentos. En virtud de dicho mandato legal es que se dictaron cuatro reglamentos: uno dictado por el presidente de la República mediante el Ministerio de la Secretaría General de la Presidencia, que se tradujo en el Reglamento 71, publicado el jueves 28 de agosto de 2014, que se dictó para regir la Administración del Estado.

Por otro lado, cada rama del Congreso Nacional aprobó su propio reglamento. La Cámara de Diputados lo aprobó el día 27 de noviembre de 2014 y el Senado el día 26 de noviembre del 2014.

Finalmente, cabe destacar el reglamento dictado por Contraloría General de la República, mediante la Resolución 570 del 21 de noviembre de 2014, destinada a regir el lobby y la gestión de intereses particulares ante dicho órgano.

\section{Vacíos y problemas de la Ley 20.730}

La regulación del lobby se enmarca en cuatro ejes esenciales dentro de la agenda de modernización del Estado. Los otros pilares planteados como relevantes son: la regulación y prevención del conflicto de intereses, el control y transparencia del financiamiento de los partidos políticos y el financiamiento de las campañas políticas.

La Ley 20.730 intenta regular la actividad de lobby para reforzar que el actuar de los funcionarios públicos y autoridades sea cada vez más probo y transparente hacia la ciudadana. En este sentido, el hecho de que se haya finalmente publicado una ley 
en esta materia constituye desde ya un avance para conseguir tales fines. No obstante, esta normativa plantea ciertas falencias.

Existe una latente diferencia entre las obligaciones creadas para los lobbistas o gestores de intereses y los funcionarios públicos o las autoridades. ${ }^{24}$ En este sentido, la mayoría de las obligaciones recaen en el sujeto pasivo de lobby, lo que deja en descubierto una gran desproporcionalidad respecto de lo que debe cumplir el sujeto activo. Destaca en este aspecto la ausencia de una regulación de códigos de conducta mediante una ley o normas de integridad, transparencia y probidad que deben regir a quienes hagan lobby ante el sector público.

Otro gran problema de la Ley 20.730 es en relación con las sanciones que consigna. Las sanciones contempladas para los lobbistas y gestores de intereses particulares son solamente multas ante la omisión o inexactitud de la información, y su monto máximo puede ascender a 50 UTM. De este modo, dichas sanciones son claramente poco disuasivas, por cuanto el contexto según el cual un lobbista actúa generalmente implica o conlleva también la actuación de un poder económico por detrás que tiene la posibilidad de pagar a un tercero para que ejerza influencia en la autoridad. De esta forma, una multa monetaria de un bajo monto no será un gran disuasivo a que el lobbista no otorgue cierta información.

Además, en este sentido, existe una clara diferencia con los proyectos de ley de los años 2003 y 2008, por cuanto en ellos existía un Registro de Lobbistas previo a la reunión, y el lobbista tenía la obligación de inscribirse e informar ciertos datos. En caso de incumplimiento de las obligaciones descritas, los lobbistas podían ser castigados con un amplio abanico de sanciones, desde multas hasta la suspensión e incluso eliminación del registro. No obstante, la indicación sustitutiva al cambiar el foco de regulación hacia el sujeto pasivo de lobby también eliminó el Registro de Lobbistas y la mayoría de las obligaciones que éste significaba. De este modo, las mayores sanciones son hacia el sujeto pasivo de lobby, en quien recae el deber de informar las audiencias y reuniones sostenidas y según el Reglamento 71, de verificar la exactitud y completitud de la información entregada. En caso de ausencia de información de parte del sujeto pasivo, o de inexactitud, y su reincidencia, puede llegar a configurarse bajo el artículo 18 inciso final de la Ley 20.730 una falta grave a la probidad.

Asimismo, de acuerdo con el artículo 14 de la Ley 20.730, ante cualquier infracción de parte del sujeto pasivo de las obligaciones contempladas en la ley, le regirá sus respectivos estatutos dependiendo de qué tipo de autoridad o funcionario público sea.

24. Esto fue discutido durante la tramitación de la indicación sustitutiva, y fue planteado por el senador Walker: «iQue deberemos efectuar a futuro? Dos cosas. Primero, garantizar un mayor equilibrio -que no lo veo en este proyecto- entre las obligaciones establecidas para las autoridades y funcionarios (sujetos pasivos) con relación a las de los lobbistas y gestores de intereses particulares». Extraído de Historia Fidedigna de la Ley 20.730, folio 598. 
Por otro lado, existe un vacío legal en la Ley 20.730 y que ningún reglamento hasta hoy resuelve. El inciso penúltimo del artículo 12, que consagra las obligaciones de los lobbistas y gestores de intereses, señala que la omisión inexcusable de la información requerida o falseada será penada con una multa. No obstante, dicho artículo no señala qué autoridad deberá aplicar dicha sanción cuando el sujeto activo infringe la obligación de informar a la autoridad ante la cual hará lobby. Los reglamentos mencionados tampoco se hacen cargo de ello.

Finalmente, se consagra un deber de denuncia para todo funcionario público respecto de cualquier incumplimiento de esta ley.

Otro vacío legislativo dice relación con las comunicaciones efectuadas a través de correos electrónicos $u$ otros medios. En este sentido, la ley no zanja si acaso las comunicaciones realizadas por otros medios de comunicación pueden ser considerados medios viables para realizar lobby o no. Del concepto de audiencia o reunión otorgados por la ley y los reglamentos, por ejemplo, los correos debieran ser considerados excluidos como objeto de la ley, puesto que ha habido reiterados casos en que se ha considerado parte del derecho a la privacidad que posee toda persona.

La Ley 20.730, al establecer que deben consignarse las audiencias y reuniones y el concepto de éstas en los reglamentos, parece desincentivar las reuniones programadas y motivar a que las discusiones o conversaciones relevantes sean por medios telefónicos o electrónicos, ya que no quedarían bajo la obligación de registrarse según la ley y sus reglamentos.

Finalmente, otro problema que plantea la Ley 20.730 dice relación con su artículo 6 número 4. Dicho artículo excluye como actividad de lobby de «toda información entregada a una autoridad, que la haya solicitado expresamente para efectos de realizar una actividad o adoptar una determina decisión, dentro de su ámbito de competencia». Esta exclusión pareciera hacer irrisoria toda la legislación de lobby en este sentido, ya que bastaría con que la autoridad afirme que un sujeto activo le solicitó la entrega de informes con antecedentes en uno u otro sentido para excluir aquello como una actividad de lobby y, por ende, que no debiese registrarse.

\section{Distintas herramientas de regulación de lobby: el Registro de Audiencia Pública versus los Registros de Lobbistas}

Los países que han regulado el lobby lo han hecho bajo diferentes modelos y fórmulas. Una de las herramientas principales a efectos de regular esta actividad constituye lo que se denomina el Registro de Lobbistas. Al momento de legislar en Chile este tema, y conforme ya se anticipó, uno de los principales focos de discusión parlamentaria fue si acaso debía regularse el lobby mediante la creación de un Registro de Lobbista. 
En este sentido, la opción chilena fue novedosa dentro del marco de regulación comparada, ya que estableció los denominados Registros de Audiencia Pública. Ahora bien, ¿cómo funciona exactamente el Registro de Audiencia Pública contemplado en la ley? ¿Es lo mismo esta herramienta regulatoria que un Registro de Lobbistas? ¿Bajo qué criterios se han establecido los Registros de Lobbistas a nivel comparado? Estos cuestionamientos son los que se abordarán a continuación.

\section{Los Registros de Lobbistas}

Dentro de las herramientas regulatorias del lobby, encontramos el Registro de Lobbistas, que ha sido utilizado a nivel comparado. ${ }^{25}$ Ahora bien, respecto de esta herramienta regulatoria se discuten ciertos temas, tales como: i) quiénes son los que deben inscribirse, ii) quiénes serán exceptuados del registro, iii) cuál será la información requerida (y si incluirá o no información financiera), iv) las maneras de actualización de la información y vi) sanciones ante el incumplimiento del deber de registrarse (Biblioteca del Congreso Nacional, 2012a: 12).

Una de las mayores discusiones que plantea esta herramienta es si, en caso de haber un Registro de Lobbistas, debe ser este voluntario u obligatorio. El modelo de la Unión Europea ha establecido el registro ante la Comisión de carácter voluntario. Por otro lado, el modelo estadounidense refleja la otra opción legislativa, en el sentido que cualquier lobbista que desee influir en una autoridad o funcionario público debe previamente inscribirse como tal para poder actuar. No obstante, en Estados Unidos, donde impera el Registro de Lobbistas, ha habido ciertas críticas en cuanto a su funcionamiento, ya que estos registros «son de difícil exigibilidad, excesivamente burocráticos, con altos costos en tiempo y recursos [...] y objeto del problema de exceso de información». ${ }^{26}$

Ahora bien, en torno a las interrogantes planteadas respecto de cómo debiesen regularse los aspectos principales de los Registros de Lobbistas, cabe recordar que existen diversos modelos de regulación:

Respecto de la interrogante de quiénes deben registrarse, «el alcance del registro se encuentra en gran parte determinado por la definición legal de «lobby» y de lobbista». ${ }^{27}$

En este sentido, existen tres modelos de incorporación de personas en el registro de lobbista: a) una determinada por ser un profesional que ejerce lobby como acti-

25. Esto ha sido así en países tales como Estados Unidos, Canadá, la Unión Europea y Australia, entre otros.

26. José Francisco García, «La tercera vía chilena», La Tercera, 14 de julio de 2013, disponible en http:// bit.ly/2l8xnSF.

27. José Francisco García, «La tercera vía chilena». 
vidad remunerada (como sucede, por ejemplo, en Estados Unidos, Canadá y Reino Unido), b) otro en base a que se ejerza lobby exclusivamente a nombre de un tercero (como por ejemplo, en Australia) y, c) finalmente un modelo que está determinado exclusivamente por el objeto de influir en instituciones públicas (como el caso de la Unión Europea). En este sentido, la legislación chilena parece acercarse más al modelo de la Unión Europea en el tema del Registro de Audiencia Pública, ya que lo determinante de quedar incluido en el registro es la actividad de influir en la autoridad más que si es un lobbista profesional remunerado o no. ${ }^{28}$

En torno a los exceptuados del registro, existen cuatro opciones regulatorias. La primera dice relación al tiempo y recursos destinados al lobby (opción estadounidense) (Biblioteca del Congreso Nacional de Chile, 2012: 11). Una segunda clasificación dice relación con el tipo de persona u organización que ejecuta el lobby (Biblioteca del Congreso Nacional de Chile, 2012: 12). Un tercer modelo dice relación con el contenido potencial de la actividad de lobby realizada (Biblioteca del Congreso Nacional de Chile, 2012: 12).

Finalmente, la opción chilena fue excluir ciertas actividades de la ley de lobby y la obligación de consignarse en el Registro, por lo que, en este sentido, se asimilaría más al tercer modelo regulatorio, esto es, el modelo europeo.

En torno a la información requerida a ser revelada o proporcionada por los registros, hay discusión en torno a su extensión a nivel de la OCDE. Una encuesta realizada por la organización respecto de qué tipo de información debiese ser pública concluyó:

los lobbistas tendían a compartir la visión del gobierno [...] una de las razones por la que los lobbistas se resisten a revelar información financiera está en que esa información puede incluir secretos profesionales o divulgar en particular cómo un lobbista conduce sus propios asuntos de lobby (OCDE, 2013: 52; traducción propia).

En este sentido, existen dos modelos regulatorios al respecto: uno que sí exige la revelación de información financiera (como en el caso de Estados Unidos) y otro que no los exige (como en el caso de Reino Unido). En ambos, el núcleo de información a ser solicitada por el Registro de Lobbistas es respecto de los motivos del lobby, la identificación de los beneficiarios del mismo y las instituciones que son su objeto de atención (OCDE, 2009: 29).

Un problema en torno a esta materia es que debe haber un cuidadoso balance entre el derecho de todo ciudadano a informarse sobre ciertos aspectos de la actividad de lobby y, por otro lado, que la información destinada a entregarse no sea excesiva, sino que la precisa. De esta manera, se evita que se produzca un exceso de información, lo cual colapsaría el sistema y su objetivo, que es saber exactamente quién influencia a quién y para qué o en qué aspectos. 
En torno a la actualización de información, los modelos de regulación difieren en torno a los plazos de meses o semanas. En «Canadá, ésta debe ser mensual; en Estados Unidos y el Reino Unido es trimestral; Australia establece una periodicidad semestral; la Unión Europea contempla la obligación de actualizar de manera anual» (OCDE, 2013: 1; traducción propia).

Finalmente, respecto de las sanciones ante el incumplimiento del deber de registrarse, existen diversas sanciones de todo tipo de índole (penales, civiles y administrativas) (Biblioteca del Congreso Nacional de Chile, 2012: 18).

Respecto de las sanciones administrativas, pueden ser la suspensión del Registro de Lobbistas o su eventual eliminación de éste. Chile ha optado por sancionar la omisión de información en el Registro de Audiencia Pública a las autoridades con multas y a los lobbistas y gestores también. Pero en estricto sentido, no hay sanciones ante el incumplimiento del deber de registrarse, puesto que es la autoridad o funcionario público quien debe informar las reuniones o audiencias sostenidas con los sujetos activos de lobby.

\section{La opción regulatoria chilena: los Registros de Audiencia Pública}

Conforme se adelantó en el acápite anterior, Chile ha optado por una vía regulatoria totalmente distinta a los tres modelos identificables en torno a la regulación del lobby a nivel de países pertenecientes a la OCDE. En este sentido, no se cuenta con un Registro de Lobbistas, sino que con uno de Audiencia Pública.

Esta opción vino en parte a destrabar uno de los aspectos más polémicos durante la tramitación legislativa de la regulación del lobby. En efecto, la existencia de un registro en donde obligatoriamente deberían inscribirse todos quienes quisieran ejercer lobby (con la consiguiente dificultad de que muy pocas personas querrían identificarse como lobbistas), aparejado a la creación de diversos registros públicos de lobbistas que ambos proyectos del 2003 y 2008 proponían, no fomentaba de manera eficiente la transparencia en esta materia. Aquello fue doblemente criticable, ya que se proponía restringir la actividad del lobby sólo a quienes profesionalmente lo ejercían, lo que afecta la igualdad ante la ley de las personas, y, además, se creaba indirectamente una limitación para éstas de acceder a sus representantes o autoridades. Pese a dichas dificultades, no todos los parlamentarios estuvieron de acuerdo con este nuevo enfoque y se opusieron a la eliminación del Registro de Lobbistas. ${ }^{29}$ Por lo mismo, algunos diputados propusieron la reincorporación del Registro de Lobbistas dentro de la normativa propuesta, pero esta enmienda fue

29. Historia fidedigna de la Ley 20.730, folio 385. En este sentido, el diputado Díaz afirmó: «El Gobierno que ha planteado una regulación especial y sui generis del lobby, en que se excluye el registro de sujetos activos, formula las declaraciones comentadas, cabe concluir que en esto existe una contradicción». 
rechazada por estimarse que era una materia de exclusiva competencia del Presidente de la República. ${ }^{30}$

Ahora bien, el Registro de Audiencia Pública difiere en diversos aspectos de lo que se entiende por Registro de Lobbistas por diversas razones: i) el primero, contemplado en la Ley 20.730, opera de forma automática o previa a la realización de una reunión según el artículo 13 inciso segundo.$^{31}$ En el caso de los Registros de Lobbistas, operan previo a la realización de cualquier reunión que desea tener el sujeto activo para influir. Por otro lado, ii) el Registro de Lobbistas es una herramienta que debe cumplir dos propósitos: consignar quiénes son lobbistas (juntamente con toda la información que aquello implica) y a su vez, una serie de obligaciones y deberes para quienes son parte del mismo. En este último aspecto es que flaquea la legislación chilena, y que conlleva a afirmar que el Registro de Audiencia Pública es más bien una forma sui generis que mezcla lo que podría ser un Registro de Lobbistas con lo que es transparentar meramente una agenda de actividades de una autoridad o funcionario público.

A su vez, iii) otro tema que no está zanjado es en qué forma se verificará la información entregada al funcionario público o autoridad. En este sentido, el Reglamento 71, en su artículo 11, otorga la posibilidad al sujeto pasivo de lobby que, con posterioridad a la reunión, dentro de diez días, solicite información adicional. Ante el incumplimiento del sujeto activo de proporcionar la información requerida, el Reglamento se remite al artículo 14 de la Ley 20.730.

Por otro lado, iv) otra diferencia entre el Registro de Lobbistas y el de Audiencia Pública está en su objetivo. El objetivo del Registro de Lobbistas es consignar y transparentar a la ciudadanía quiénes son los lobbistas profesionales que se dedican a esta actividad. El objeto de la formulación del otro Reglamento reside en transparentar las actividades diarias de las autoridades, con independencia de si se reúnen con lobbistas o gestores de intereses particulares.

30. Historia fidedigna de la Ley 20.730 , folio 386 .

31. Llama la atención el artículo 13. Esta norma fue incorporada tras la discusión en comisión mixta en el Congreso Nacional. En este sentido, la historia fidedigna de la Ley 20.730 indica que esta norma «fue debatida respecto de si la obligación de registrarse debiere ser ex ante o ex post, puesto que optar por una u otra fórmula determinaría el sentido del proyecto, toda vez que las opciones implican, por una parte, regular la actividad y, por la otra, la obligación de registrarse (la modalidad norteamericana admite la inscripción previa, en tanto que la europea regula la posterior), todo lo cual varía la carga de quien es el obligado a anunciar una actividad de lobby: el lobbista o el sujeto pasivo de lobby» (folio 555). De este modo, al no poder ponerse de acuerdo los parlamentarios en este tema, consagraron ambas posibilidades de cómo consignar una posible audiencia pública. Esta norma, por lo mismo, es un poco extraña en su formulación, puesto que no se entiende cómo exactamente un registro de audiencia pública puede formarse automáticamente al sostener un particular una reunión con una autoridad o funcionario público. 
Finalmente, existe un contraste latente entre la opción regulatoria chilena y la del derecho comparado en el tema de las v) sanciones. Las sanciones en el Registro de Audiencia Pública están enfocadas principalmente al sujeto pasivo de lobby, ya que se entiende que él es quien tiene la obligación de informar sus audiencias o reuniones diarias. En cambio, en el Registro de Lobbistas, al ser una obligación del sujeto activo de inscribirse, en éste recaen casi todas las sanciones contempladas ante la ausencia de su cumplimiento. Del mismo modo, la naturaleza de las sanciones en sí también es diferente.

En definitiva, pareciera ser que pese a las críticas que se pueden formular a un Registro obligatorio de Lobbistas, quizás Chile debió optar por regular la existencia de un registro voluntario, ya que existen numerosas organizaciones que se reconocen como lobbistas y que no se opondrían a inscribirse en dicho registro. De todas maneras, es necesario reconocer que la existencia del Registro de Audiencia Pública ha contribuido a mejorar el principio de transparencia de la función pública ${ }^{32} \mathrm{y}$, más específicamente, la transparencia activa que deben mantener los órganos del Estado respecto del quehacer público.

\section{Conclusiones}

La teoría constitucional postula diversas visiones acerca de la democracia. En cada una de ellas ha estado presente, de una u otra manera, los debates acerca del rol de los grupos de interés y los grupos de presión. Tras haber examinado la problemática de la regulación del lobby desde una perspectiva jurídico-normativa, se puede concluir lo siguiente.

Hoy en día el debate sobre el posible riesgo de captura de la autoridad, y de la prevalencia del interés privado por sobre el interés público en el proceso de toma de decisiones se ha tornado aún más urgente en nuestras sociedades, donde los grandes grupos de presión influyen decisivamente en las políticas públicas de un país. Esta situación ha conllevado a una pérdida de confianza en las instituciones públicas por parte de los ciudadanos; como también a una afectación del derecho a la igualdad ante la ley y a una posible omisión en la actuación proba o poco transparente que debiese guiar el actuar de los funcionarios públicos. Es por esa razón que se ha planteado, cada vez con más fuerza, la necesidad de regular el lobby, para evitar los efectos perniciosos de esta actividad ante la ausencia de su regulación.

En este panorama internacional, nuestro país — durante los últimos diez años-

32. Este principio, según Vivanco Martínez (2008: 387), consiste en «respetar y cautelar la publicidad de los actos, resoluciones, procedimientos y documentos de la Administración, así como la de sus fundamentos, y en facilitar el acceso de cualquier persona a esta información, a través de los medios y procedimientos que al efecto establezca la ley». 
discutió acerca de la necesidad de legislar sobre la actividad de lobby. Finalmente, se aprobó la Ley 20.730 que regula el lobby y las gestiones que representen intereses particulares ante las autoridades y funcionarios. Previo a ello, los proyectos legislativos más importantes fueron las iniciativas de los años 2003 y 2008. Dichas iniciativas estuvieron entrabadas durante mucho tiempo por diversas razones. Entre las principales, estaba que los legisladores no se ponían de acuerdo sobre qué se consideraría lobby, quiénes se incluirían y si acaso habría o no un Registro de Lobbistas. Fue en este contexto que el 2013 se presentó una indicación sustitutiva que vino a cambiar el foco de regulación desde los lobbistas a centrarse más bien en las obligaciones y deberes que deben tener las autoridades y funcionarios públicos para transparentar su agenda pública. Fue tras esta indicación que se logró un mayor consenso para legislar sobre el lobby.

Pese a este gran avance que se logró con la dictación de la Ley 20.730, dicha normativa tiene ciertos vacíos y problemas. De partida, es evidente que la ausencia de una regulación de los sujetos activos del lobby, mediante el establecimiento de un Registro de Lobbistas y obligaciones y deberes para éstos propiamente tal, hace dudar si acaso la ley de lobby realmente regula dicha actividad o es más bien una ley de transparencia del quehacer público. En este sentido, el artículo 13 de la referida ley, que consagra el Registro de Audiencia Pública, al no establecer obligaciones ni deberes para los lobbistas sino que sólo regular al sujeto activo, difiere en cómo se ha entendido esta herramienta a nivel comparado. Por lo mismo, el Registro de Audiencia Pública es más bien una creación sui generis de la legislación chilena y que puede ser mejorada mediante el establecimiento de ciertos deberes para los lobbistas vía legislativa o con la imposición de un código de conducta para que los sujetos activos resguarden ciertos estándares mínimos de integridad y transparencia al tratar con las autoridades o funcionarios públicos (OCDE, 2012: 51-67).

Por otro lado, llama la atención que no haya ninguna norma que limite o restrinja el financiamiento a las campañas políticas o partidos políticos, como sí lo hacían los proyectos de ley de los años 2003 y 2008. Del mismo modo, respecto de las sanciones de la ley, se reducen a multas para los lobbistas y gestores y para los funcionarios públicos se establecen multas por ciertas omisiones de publicación o información en la agenda pública. Estas sanciones parecen ser poco efectivas y disuasivas para cumplir con su objetivo, ya que es sabido que los grandes grupos económicos de la sociedad son los que más ejercen influencia en el sector público para que se aprueben o no ciertas políticas públicas o leyes en su favor.

A modo de conclusión, la Ley 20.730 es un avance legislativo en torno a los propósitos de legislar para transparentar el quehacer público y mejorar la confianza ciudadana en las instituciones públicas. No obstante, siguen existiendo temas pendientes con la aprobación de esta ley, ya que esta normativa sui generis no deja en claro si es una ley de lobby o más bien una ley de transparencia. Pareciera ser necesario replan- 
tearse respecto de cuál es el objeto real de la ley y, por otro lado, regular las omisiones o vacíos que esta normativa plantea.

\section{Referencias}

Biblioteca del Congreso Nacional de Chile (2002). Lobbying: Antecedentes generales y experiencia extranjera. Valparaíso: Unidad de Apoyo al Proceso Legislativo.

-. (2012a). Lobby, obligación de transparencia de agenda pública: Derecho comparado. Valparaíso: Asesoría Técnica Parlamentaria. Disponible en http://bit.ly/2DnUak6.

-. (2012b). Lobby en Chile: Regulación y desafíos en Transparencia. Valparaíso: Asesoría Técnica Parlamentaria. Disponible en http://bit.ly/2BU7DCY.

Castro Pedrero, Mauricio (2004). Regulación de la gestión de intereses o lobby: elementos para el debate. Santiago: Corporación Chile Transparente.

Correa Ríos, Enrique (2010). «Comunicación: Lobby y asuntos políticos». Cuadernos del Centro de Estudios en Diseño y Comunicación, 33: 101-110. Disponible en http://bit.ly/2BrqdD2.

García, José Francisco (2008). «Modelos de regulación del lobby en el derecho comparado». Revista Chilena de Derecho, 35 (1): 107-134. DOI 10.4067/So71834372008000100005.

García García, José Francisco y Soto Velasco, Sebastián (2015). «Una mirada económica al diseño constitucional chileno: impacto sobre el proceso legislativo y la acción de los grupos de interés». Ius et Praxis, 15 (1): 353-372. DOI: 10.4067/So71800122009000100012.

Guzmán Romero, Juan José (2008). «¿Capturados por nuestra suspicacia? Algunas aproximaciones acerca del origen, desarrollo y extinción de las regulaciones». Revista Chilena de Derecho, 35 (1): 9-35. DOI: 10.4067/So718-34372008000100002.

Instituto de Ciencias Sociales de la Universidad Diego Portales (2005).Élites políticas y su percepción sobre la actividad de lobby en Chile. Informe de prensa. Santiago.

INDH, Instituto Nacional de Derechos Humanos (2012). Situación de los derechos humanos en Chile. Santiago.

LaCHMANN, Werner (2012). «Grupos de interés, lobbies». En Lobby y grupos de interés (pp. 5-20). Santiago: Konrad Adenauer Stiftung.

OCDE, Organización para la Cooperación y el Desarrollo Económicos (2009). Lobbysts, governments and public trust: Increasing transparency through legislation. París: OECD Publishing.

-. (2012). Lobbysts, governments, and public trust: Promoting integrity through selfregulation. París: OCDE Publishing. 
-. (2013). Lobbysts, governments, and public trust: Implementing the OECD principles for transparency and integrity in lobbying. París: OECD Publishing.

PNUD, Programa de las Naciones Unidas para el Desarrollo (2014). Auditoría a la democracia: Más y mejor democracia para un Chile inclusivo. Santiago.

Urzúa Valenzuela, Germán (1986). Derecho político chileno. Santiago: Jurídica.

Vivanco Martínez, Ángela (2008). «Transparencia en la función pública y acceso a la información de la Administración del Estado: una normativa para Chile». Revista Chilena de Derecho, 35 (2):371-398. DOI: 10.4067/So718-34372008000200011. Von Alemann, Ulrich y Eckert, Florian (2012). «El lobbying: Política en las sombras». En En Lobby y grupos de interés (pp. 21-32). Santiago: Konrad Adenauer Stiftung. Von Beyme, Klaus (1980). Los grupos de presión en la democracia. Buenos Aires: Editorial de Belgrano.

\section{Sobre la autora}

María José Jordán Palet es abogada de la Pontificia Universidad Católica de Valparaíso, Chile. Su correo electrónico es maria.jose.jordan.p@hotmail.com. 
La Revista de Derecho Público es publicada, desde 1963, dos veces al año por el Departamento de Derecho Público de la Facultad de Derecho de la Universidad de Chile. Su propósito es la difusión de los avances del derecho público nacional e internacional y la socialización de artículos de investigación inéditos tanto de la comunidad académicas nacional e internacional.

DIRECTORA

Ana María García Barzelatto

SECRETARIO DE REDACCIÓN

Felipe Peroti Díaz

(fperoti@derecho.uchile.cl)

SITIO WEB

revistaderechopublico.uchile.cl

CORREO ELECTRÓNICO

publico@derecho.uchile.cl

LICENCIA DE ESTE ARTÍCULO

Creative Commons Atribución Compartir Igual 4.0 Internacional

La edición de textos, el diseño editorial

y la conversión a formatos electrónicos de este artículo

estuvieron a cargo de Tipográfica

(www.tipografica.cl). 